\title{
In Vitro Manipulation of Nonhuman Primate Gametes for Embryo Production and Embryo Transfer
}

\author{
Tadashi SANKAI \\ Tsukuba Primate Center, National Institute of Infectious Diseases, \\ Hachimandai-1, Tsukuba, Ibaraki 305-0843, Japan
}

\begin{abstract}
Since nonhuman primates are closely related to humans and share many physical similarities, they are important for use in research areas such as human infectious diseases, reproduction, physiology, endocrinology, metabolism, neurology and longevity. To develop and maintain these animals, we must establish techniques for in vitro manipulation of spermatozoa and eggs. For a decade my research group has been conducting basic research to establish embryo manipulation techniques and to clarify the reproductive phenomena in nonhuman primates. This article summarizes the past research on in vitro manipulation of nonhuman primate gametes, from collection of reproductive cells and in vitro fertilization to the birth of offspring after embryo transfer, as well as the current status of these research areas. The studies summarized here will directly lead to the development of standard techniques for practical and comprehensive use in nonhuman primates.
\end{abstract}

Key words: embryo, in vitro manipulation, nonhuman primate, spermatozoa

\section{Contents}

I. Introduction

II. Sperm processing

1. Sperm collection

2. Sperm quality in vivo and in vitro

3. Cryopreservation of spermatozoa

III. Oocyte processing

1. Oocyte collection

2. In vitro maturation (IVM) of oocytes

IV. Production of embryos

1. Collection of embryos fertilized in vivo

2. In vitro fertilization (IVF)

3. Intracytoplasmic sperm injection (ICSI)
V. Embryo development culture and embryo transfer

1. Embryo development culture

2. Embryo transfer (ET)

VI. Conclusion

\section{Introduction}

The field of embryo manipulation has widespread applications: to improve the reproductive efficiency of animals in captivity, to improve specific pathogen-free properties of domestic and laboratory animals, and to improve the production of laboratory animals for use as human-disease models. Reproductive techniques developed for such purposes are also applicable to

(Received 4 October 1999)

Address corresponding: T. Sankai, Tsukuba Primate Center, National Institute of Infectious Diseases, Hachimandai-1, Tsukuba, Ibaraki 3050843, Japan 
maintaining the genetic resource of endangered wild animals.

Nonhuman primates are very important animals for use in research on human infectious diseases because they are closely related to humans and share many physical and biological similarities. For the same reasons, they are also important in research on reproductive physiology, endocrinology, metabolism, and neurology. Furthermore, because of their long life span, they can be useful for research on longevity. To develop and maintain these important animal research resources, we must establish techniques for the in vitro manipulation of spermatozoa and eggs. The chronology of the principal progress made in this research area is shown in Table 1.

For a decade, my research group in reproductive technology, at the Tsukuba Primate Center, National Institute of Infectious Diseases [36, 37], has been conducting basic research to establish embryo manipulation techniques and to clarify the mechanisms of fertilization and development of preimplantation embryos in nonhuman primates. This article summarizes our past and present studies on the quality of fresh and frozenthawed spermatozoa, in vitro maturation (IVM) of germinal-vesicle stage oocytes, in vitro fertilization (IVF), intracytoplasmic sperm injection (ICSI), and embryo transfer (ET).

\section{Sperm Processing}

\section{Sperm collection}

Many methods have been attempted for the collection of nonhuman primate spermatozoa $[14,29,35,38$, $50,61,62,98,118]$. Of these, the two most commonly used methods are collecting from ejaculate semen and from the epididymis. My research group has collected fresh semen from sexually mature male cynomolgus monkeys (Macaca fascicularis) by rectal stimulation with an electrode. This method has the potential for obtaining semen from any male. Although the semen is collected in trace amounts only, the volume is usually sufficient for use in IVF and ICSI. We have also collected epididymal spermatozoa from the epididymis after death. In this method, the epididymides were removed after euthanasia and then the tails of the epididymides were minced in medium and incubated for approximately $10 \mathrm{~min}$ in an atmosphere of humidified
$5 \% \mathrm{CO}_{2}$ and $95 \%$ air. The sperm suspension is poured on top of $90 \%$ Percoll in a disposable tube and then centrifuged at $800 \mathrm{Xg}$ for $10 \mathrm{~min}$. A large quantity of spermatozoa with good motility can be collected from the resulting sediment. To collect spermatozoa with good motility, it is best to collect sperm as soon as possible after removal of the epididymis but we succeeded in collecting such spermatozoa up to $24 \mathrm{hr}$ after removal by keeping the epididymides in mineral oil at $5^{\circ} \mathrm{C}$. This storage procedure was successfully applied to Japanese monkeys (Macaca fuscata). The fertility of the spermatozoa was confirmed by an IVF examination [83]. We also developed a rota-cut needle used for testicular biopsies in cynomolgus monkeys. This needle makes it easy to collect cells from testis [57]. We are using such biopsied cells in basic studies, such as direct cell injection into eggs $[44,67,70]$.

\section{Sperm quality in vivo and in vitro}

Although spermatozoa show active progressive motility immediately after collection, they are not capable of fertilizing eggs. The spermatozoa ejaculated into a vagina acquire the capacity to penetrate the eggs after physiological and biochemical changes caused by traveling into the oviduct. Sperm capacitation in vivo is well known, and females became impregnated when artificially inseminated with semen collected by rectal electrode stimulation.

When spermatozoa are used in vitro, the quality of the spermatozoa (e.g., capacitation, acrosome reaction, interaction with zona pellucida, penetration) must be accurately assessed $[106,107]$. Sperm quality in vitro, such as motility and intensity, was discussed in the previous report [59]. To evaluate sperm quality, my research group is currently reprogramming an objective analysis system (video image processing with a computer), originally developed for human sperm analysis, for use with cynomolgus monkey spermatozoa.

The medium used for nonhuman primate spermatozoa in vitro must be optimal for that particular species. Among the several types of media reported, my research group selected TYH medium [103], which was developed for IVF of mouse eggs. Furthermore, by incubation of the spermatozoa in medium that contained caffeine and dibutyryl cyclic AMP, sperm capacitation and hyperactivated motion were induced in spermatozoa of the rhesus monkey (Macaca mulatta) [11], the 
Table 1. Principal chronology in the 1970s, 1980s and 1990s on in vitro manipulation of nonhuman primate gametes

\begin{tabular}{|c|c|c|c|}
\hline Year & Investigator (Ref. No.) & Monkey species & Research area (key words) \\
\hline 1972 & Leverage et al. (55) & Rhesus & sperm cryopreservation \\
\hline 1973 & Gold et al. (30) & Squirrel & IVF, 2-cell \\
\hline 1974 & Cho et al. (16) & Cynomolgus & sperm cryopreservation, artificial insemination \\
\hline 1976 & Denis et al. (19) & Squirrel & sperm cryopreservation \\
\hline 1978 & Mahone et al. (60) & Cynomolgus & sperm cryopreservation \\
\hline 1979 & Gould (27) & Baboon & IVF \\
\hline 1979 & Kuehl et al. (48) & Squirrel & IVF, cleavage \\
\hline 1982 & Kreitmann et al. (47) & Cynomolgus & IVF, early morula \\
\hline 1983 & Dukelow et al. (20) & Squirrel & IVF \\
\hline 1983 & Bavister et al. (8) & Rhesus & IVF, early morula \\
\hline 1983 & Gould (28) & Chimpanzee & IVF, 4-cell \\
\hline 1984 & Boatman et al. (11) & Rhesus & sperm capacitation in vitro \\
\hline 1984 & Clayton et al. (17) & Baboon & IVF, offspring \\
\hline 1984 & Pope et al. (75) & Baboon & embryo cryopreservation, offspring \\
\hline 1984 & Bavister et al. (7) & Rhesus & IVF, offspring \\
\hline 1984 & Balmaceda et al. (5) & Cynomolgus & IVF, offspring \\
\hline 1986 & Balmaceda et al. (4) & Cynomolgus & IVF, embryo cryopreservation, offspring \\
\hline 1988 & Lopata et al. (58) & Marmoset & IVF, blastocyst, offspring \\
\hline 1989 & Gould et al. (31) & Chimpanzee & sperm cryopreservation \\
\hline 1989 & Fujisaki et al. (24) & Cynomolgus & IVF, morula \\
\hline 1989 & Cranfield et al. (18) & Pig-tailed & IVF, early cleavage stage \\
\hline 1989 & Wolf et al. (115) & Rhesus & IVF, embryo cryopreservation, offspring, hatched blastocyst \\
\hline 1989 & Huntress et al. (38) & Gorilla & IVF \\
\hline 1990 & Tollner et al. (100) & Cynomolgus & sperm cryopreservation, artificial insemination \\
\hline 1990 & Gould (29) & Chimpanzee, Gorilla & gamete collection, sperm cryopreservation \\
\hline 1990 & Lanzendorf et al. (54) & Rhesus & IVF, embryo cryopreservation, twins \\
\hline 1991 & Morgan et al. (66) & Rhesus & IVM, IVF \\
\hline 1991 & Sankai et al. (79) & Cynomolgus & IVF, blastocyst \\
\hline 1991 & Lambert et al. (49) & Gorilla & sperm cryopreservation, hamster test \\
\hline 1992 & Lanzendorf et al. (53) & Gorilla & partial zona dissection, frozen-thawed spermatozoa \\
\hline 1993 & Sankai et al. (81) & Cynomolgus & dead female, IVM, IVF \\
\hline 1993 & Seier et al. (90) & African green & sperm cryopreservation \\
\hline 1993 & Wilton et al. (112) & Marmoset & IVM, IVF, 32-cell \\
\hline 1994 & Alak et al. (2) & Rhesus & IVM \\
\hline 1994 & Sankai et al. (84) & Cynomolgus & sperm cryopreservation, IVF, hatched blastocyst \\
\hline 1994 & Zhang et al. (123) & Rhesus & IVF, developmental culture, hatched blastocyst \\
\hline 1995 & Joslin et al. (42) & Orangutan & IVF \\
\hline 1995 & Thomson et al. (99) & Rhesus & embryonic stem cell \\
\hline 1996 & Lanzendorf et al. (51) & Cynomolgus & IVM, IVF, blastocyst \\
\hline 1997 & Sankai et al. (78) & African green & IVF, expanded blastocyst \\
\hline 1997 & Sankai et al. (83) & Japanese & sperm cryopreservation, IVF, 8-cell \\
\hline 1997 & Sankai et al. (85) & Red-bellied tamarin & IVM \\
\hline 1997 & Pope et al. (72) & Gorilla & IVF, frozen-thawed spermatozoa, offspring \\
\hline 1997 & Meng et al. (63) & Rhesus & nuclear transfer, offspring \\
\hline 1998 & Ogonuki et al. (67) & Cynomolgus & ICSI, partial zona dissection, morula \\
\hline 1998 & Hewitson et al. (34) & Rhesus & ICSI, hatched blastocyst \\
\hline 1999 & Wolf et al. (113) & Rhesus & nuclear transfer, fibroblast, embryonic stem cell, cleavage \\
\hline 1999 & Hewitson et al. (33) & Rhesus & ICSI, offspring \\
\hline 2000 & Torii et al. (101) & Japanese & IVF, offspring \\
\hline
\end{tabular}


pig-tailed monkey (Macaca nemestrina) [18], and the cynomolgus monkey $[5,56]$. Our study also confirmed this finding in cynomolgus monkeys [84], Japanese monkeys [83], and African green monkeys (Cercopithecus aethiops) [78]. This finding in vitro may be characteristic of nonhuman primate spermatozoa. For cynomolgus monkeys, the presence of hyperactivated spermatozoa was observed after incubation for 6 to 8 $\mathrm{hr}$, and the fertility of these spermatozoa was confirmed by IVF examination. Changes in the sperm acrosome or the plasma membranes were also observed by electron microscopy (Fig. 1-A, B). For African green monkeys, hyperactivation was induced with an incubation time shorter than that for cynomolgus monkeys, and the spermatozoa incubated for 4 to $6 \mathrm{hr}$ were able to fertilize eggs in vitro [78]. Sperm quality is known to differ according to the animal species, and, as we expected, our experimental results showed such differences among the various species of nonhuman primates.

\section{Cryopreservation of spermatozoa}

Reproductive technologies such as sperm cryopreservation are necessary to maintain the genetic resources of valuable experimental-model animals as well as those of endangered nonhuman primates.

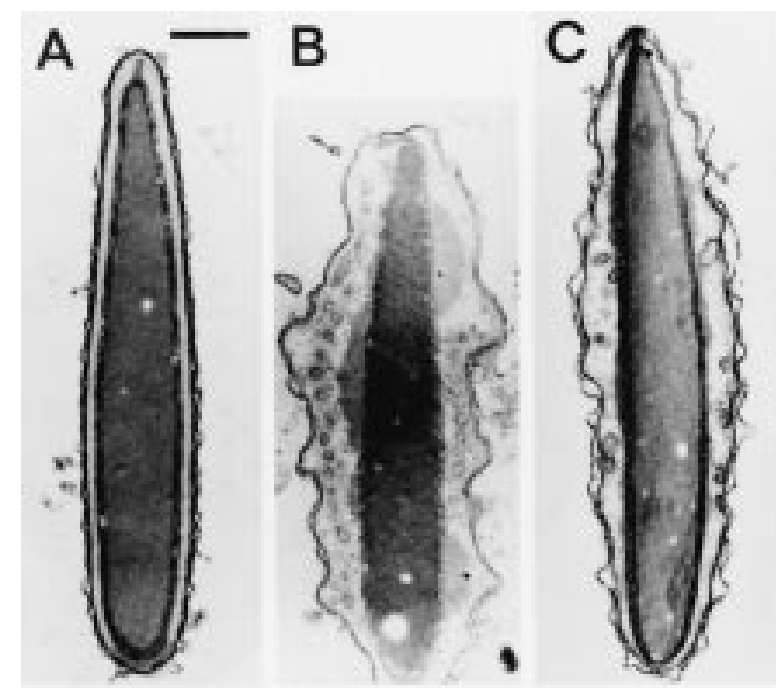

Fig. 1. Heads of cynomolgus monkey spermatozoa observed by transmission electron microscopy. (A) Fresh spermatozoa shortly after collection. (B) Fresh spermatozoa incubated for $8 \mathrm{hr}$. (C) Frozen-thawed spermatozoa immediately after thawing. Scale bar represents $0.5 \mu \mathrm{m}$.
Among the more than 200 species of nonhuman primates, only a few have been used for sperm cryopreservation studies. Successful freezing of spermatozoa has been reported for cynomolgus monkeys [15, 16, 60, 100], rhesus monkeys [55, 77], baboons (Papio anubis) [46], squirrel monkeys (Saimiri sciureus) [19], African green monkeys [90], chimpanzees (Pan troglodytes) [31], and gorillas (Gorilla gorilla gorilla) $[38,49]$. To freeze spermatozoa from cynomolgus monkeys, we prepared a semen-diluting medium, TTE (Tes, Tris, egg yolk base) [84]. After being frozen in TTE medium and glycerol and then thawed, spermatozoa with high motility were obtained. The quality of this frozen-thawed spermatozoa was determined by means of a zona pellucida penetration assay [116]. It is known that only capacitated spermatozoa can penetrate the zona pellucida when kept in a highly concentrated salt solution. In our zona pellucida penetration assay, frozen-thawed spermatozoa that were preincubated for $2 \mathrm{hr}$ penetrated the zona pellucida, whereas fresh spermatozoa preincubated for the same time did not. Furthermore, these $2 \mathrm{hr}$ preincubated frozen-thawed spermatozoa were capable of fertilization by IVF examination, whereas the $2 \mathrm{hr}$ preincubated fresh spermatozoa were not. This suggests that our freezethaw method may damage the plasma membranes of spermatozoa and induce acrosome reaction-like changes [84]. By electron microscopy, we confirmed the morphological changes in frozen-thawed spermatozoa; the acrosome was swollen or vesiculated immediately after thawing (Fig. 1-C) (Okada et al., manuscript in preparation). These findings show that our freeze-thaw method favorably affects the use of IVF examination, because, compared with fresh spermatozoa, the frozenthawed spermatozoa were capable of fertilization in vitro with shorter preincubation times or without preincubation. Nevertheless when the frozen-thawed spermatozoa are used in vivo, such as in artificial insemination, they are not suitable because they have already shown signs of capacitation or an acrosome reaction.

This sperm cryopreservation technique, established for cynomolgus monkeys, was also tried in Japanese monkeys, African green monkeys, and red-bellied tamarins (Saguinus labiatus). The results of sperm cryopreservation in Japanese monkeys were similar to those for cynomolgus monkeys. Because both these 
monkeys belong to the same genus (Macaca monkeys), the results suggest that our sperm cryopreservation method can be used for spermatozoa from the same genus. In contrast, African green monkey spermatozoa did not retain their active progressive motility. Although the spermatozoa from red-bellied tamarins retained progressive motility, the motility level was lower than that of cynomolgus monkeys or Japanese monkeys. These results demonstrate that the so-called "freeze-tolerance" of sperm, assessed by their motility, differs among the nonhuman primate species. Many aspects of freeze tolerance therefore need to be clarified for the development of a practical and effective method of sperm cryopreservation for nonhuman primates. This method might then be used for spermatozoa of all animal species.

Attempts have recently been made to study ICSI in nonhuman primates. We have reported the use of ICSI in cynomolgus monkeys [67]. When ICSI is used to create embryos, because the motility of the sperm is not a serious problem, cryopreservation of the sperm to retain motility is not needed. But one of our research aims is to reproduce in vitro exactly the same reproductive phenomenon as that seen in vivo. Spermatozoa that have retained their motility are therefore essential for such studies.

\section{Oocyte Processing}

\section{Oocyte collection}

Oocytes are usually collected from mammals after the development of multiple follicles has been induced by the administration of hormones. For nonhuman primates, researchers have used eCG (equine chorionic gonadotropin) [12, 18, 24, 41, 65], FSH (follicle-stimulating hormone) $[18,43,45,48,52,54,71,86,109$, 120-122] and hMG (human menopausal gonadotropin) $[3,5,23,32,41-43,65,105]$. My research group has used eCG, which produced a strong response in ovaries to induce follicle development. Injections of eCG were given intramuscularly eight times during the menstrual cycle (days $3,5,7,9,11,12,13$ and 14) to cynomolgus monkeys [84], Japanese monkeys [82, 83] and African green monkeys [78]. Numerous follicles developed after hormone administration (Fig. 2), sometimes over 100 follicles per female. Only one follicle is spontaneously developed in primates. For oocyte maturation,

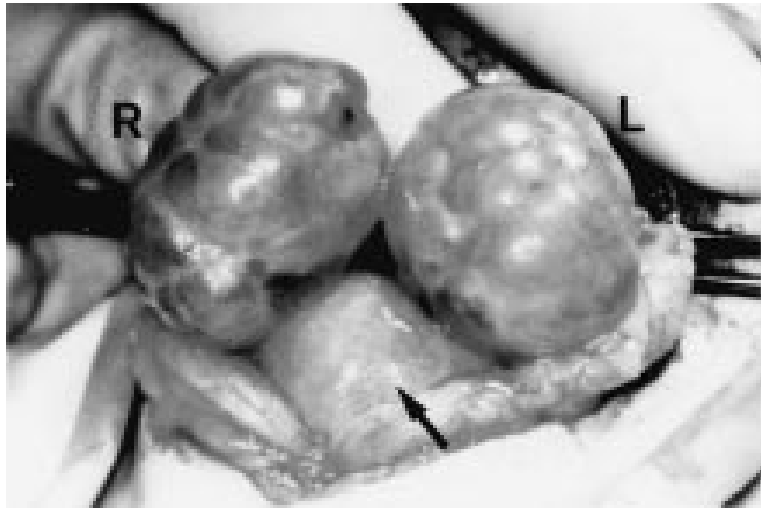

Fig. 2. Cynomolgus monkey ovaries treated with eCG and hCG, showing numerous developed follicles. R and L indicate right side and left side of ovaries, respectively, and the arrow indicates the uterus. Oocytes were obtained from the follicles and used for IVF.

hCG (human chorionic gonadotropin) was also administered intramuscularly on the morning after the last eCG injection. Mature oocytes were surgically collected 28 to $43 \mathrm{hr}$ later: while the animal was under anesthesia, ovaries were exposed through an abdominal incision, and the contents of enlarged follicles were aspirated. This technique for eCG and hCG injections can induce follicle development and is useful for the collection of mature oocytes, but technical problems in preventing the production of antibodies to administered hormones need to be solved [9]. Furthermore, individual differences in the number of developed follicles and collected oocytes must be controlled. The quality of oocytes, which affects the experimental results, will be improved by the choice of administered hormones or perhaps by the timing of administration. Some reports have shown that FSH or hMG administration is better than eCG administration for oocyte collection. We are therefore now using hMG in our studies.

Ovary stimulation of juvenile monkeys has been reported [45], and we have also studied oocyte collection in sexually immature cynomolgus monkeys. Our results show that follicle development can be induced in sexually immature females, irrespective of the menstrual cycle. Only slight individual differences in the number of developed follicles and collected oocytes were evident.

We also collected oocytes from the ovaries of females who had died by accident, and therefore collection 
took place at an unspecified time in the menstrual cycle [81], but the quality of the oocytes deteriorated at a faster rate before oocyte collection than in similar recovery of spermatozoa (see section II. 1). Techniques used in IVM were also needed, because most of the collected oocytes were at the GV (germinal vesicle) stage.

\section{In vitro maturation (IVM) of oocytes}

My research group succeeded in IVM of oocytes collected at the GV stage from cynomolgus monkeys, Japanese monkeys and red-bellied tamarins [80, 81, 85], and such mature oocytes from cynomolgus monkeys were fertilized in vitro. As the maturation medium, we used TCM-199 or CMRL-1066 containing 10\% fetal calf serum and supplemented with hCG, FSH or eCG. The resulting cultured GV-stage oocytes matured in 24 to $72 \mathrm{hr}$. Unfortunately this wide range in the culture period means that there is as yet no practical use for this method, but excellent results have been reported for IVM for metaphase I or GV-stage oocytes from rhesus monkeys [1, 2, 23, 51, 66, 81, 88, 89, 93, 117]. Those studies demonstrated that the techniques used to produce mature oocytes in vitro may be effective in the fertilization of nonhuman primates.

\section{Production of Embryos}

\section{Collection of embryos fertilized in vivo}

Collection of embryos fertilized in vivo in the oviduct or in the uterus is the basis of embryo collection methods. One embryo can be collected from a female mated through a natural menstrual cycle by flushing the oviduct or the uterus via an abdominal incision while the animal is anesthetized. To collect numerous embryos, not only methods to induce follicle development but also methods to induce ovulation must be developed. Methods for the induction of ovulation have been reported [32, 43], and an embryo collection method that involves flushing the entire reproductive tract has been established for the rhesus monkey [25, 26, 91, 92], the baboon [73-75] and the common marmoset (Callithrix jacchus) [95, 96]. For cynomolgus monkeys, the technique for cannulation to the uterus through the cervical canal [102] has been developed, a technique that my research group has successfully used. Because of this technique, the collection of nonhuman primate embryos at the morula or blastocyst stage has become technically feasible. Recently, an embryonic stem cell line was successfully isolated from a rhesus monkey embryo collected by this technique [99].

\section{In vitro fertilization (IVF)}

Two methods are commonly used to create embryos in vitro; IVF and ICSI. An IVF technique has been developed and successfully used for several types of nonhuman primates $[20,21,24,27,38,40,42,72,80$, $112,114,115,117]$. For example, we first reported IVF with frozen-thawed spermatozoa from cynomolgus monkeys, in which the embryo obtained developed to the hatched blastocyst stage [84] (Fig. 3). Furthermore, we first reported using IVF in Japanese monkeys $[82,83]$ and African green monkeys [78]. In our study of red-bellied tamarins, no eggs became fertilized after insemination in vitro [85] when we used frozen-thawed spermatozoa collected from the epididymis and mature oocytes obtained by in vitro culture of GV-stage oocytes collected from ovaries. Nevertheless the reasons for the lack of fertilization remain unclear, because many examination steps are needed to determine fertilization.

In these IVF studies, difficulties arose in obtaining a sufficient number of gametes from nonhuman primates. This means that experience gained in doing several experiments is needed when judging results and that experiments should be repeated for confirmation and reproducibility.

\section{Intracytoplasmic sperm injection (ICSI)}

The ICSI technique has been reported for collecting embryos from in vitro in the cynomolgus monkey [67] and the rhesus monkey [33, 34, 64]. For example, my research group first used ICSI in cynomolgus monkeys [67], and we expect that this technique will achieve a fertilization rate higher than that for IVF. Recent studies in reproductive biology on fertilization in mice show that offspring can be obtained by intracytoplasmic injection of spermatid from testis $[44,70]$. Although this fertilization phenomenon does not occur naturally, these data provide valuable additional information on testicular cells and eggs. Human offspring have already been obtained by intracytoplasmic injection of spermatid [22]. Although intracytoplasmic injection techniques are useful for preserving the male gene at the cellular level 

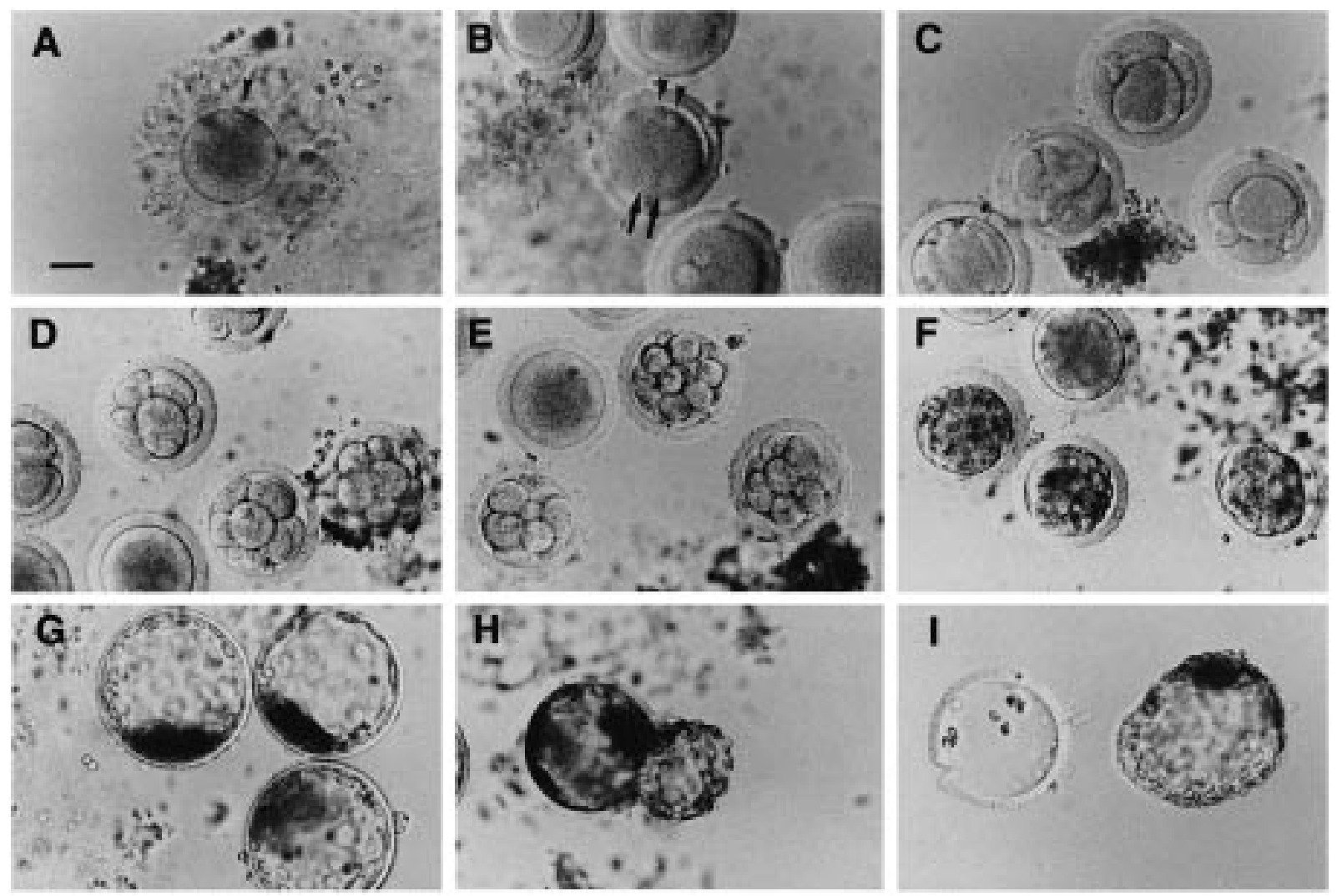

Fig. 3. Cynomolgus monkey embryos obtained by IVF with frozen-thawed spermatozoa. (A) A mature oocyte surrounded by a corona and loose cumulus cells before insemination (arrowhead indicates a first polar body). (B) Pronuclear embryos (arrows indicate female and male pronuclei, and arrowheads indicate first and second polar bodies). (C) 4-cell embryos. (D) 6- to 8-cell embryos. (E) 8- to 16-cell embryos. (F) Compacted morulae. (G) Expanded blastocysts. (H) Blastocyst hatching from zona pellucida. (I) Hatched blastocyst with empty zona pellucida. Scale bar represents $50 \mu \mathrm{m}$.

and seem to be a good possibility for gene manipulation as transgenic animals, the effectiveness and safety of the technique needs to be determined [33].

Techniques for the transfer of nuclear material from somatic cells in mammals were recently reported [108, 111]. Nuclear transfer was also tried in the rhesus monkey $[63,113]$. We therefore have begun studies on oocyte activation, pronucleus formation, pronucleus fusion and subsequent embryo development.

\section{Embryo Development Culture and Embryo Transfer}

\section{Embryo development culture}

Establishing techniques for development culture requires embryo manipulations in vitro. Various media have been used for embryo development culture. In the rhesus monkey, good results for fertilization and cleavage of oocytes in vitro have been reported in about 65 to $80 \%$ of mature ova fertilized. Of these eggs from IVF, 95\% underwent at least one cleavage division. Approximately $50 \%$ of embryos reached the blastocyst stage, with $20 \%$ hatching from the zona pellucida [6, 8]. By culturing cynomolgus monkey embryos (obtained by IVF) in Whitten's medium [110], we successfully developed the embryos to the hatched blastocyst stage [84]. We recently cultured cynomolgus monkey embryos in CMRL-1066 in petri dishes seeded with buffalo rat liver cells. The culture conditions for CMRL-1066 have been determined for rhesus monkey embryos [10, 63, 87, 109, 123], and we also obtained data for the development of such embryos to the blastocyst stage. For satisfactory use, further research must be conducted to determine such factors as the quality 
of the media or embryos at the start of the culturing, that affect the development rate.

\section{Embryo transfer (ET)}

ET is an essential technique for obtaining offspring from in vitro embryos. Establishing an efficient ET technique is therefore an important task in this research field. In 1984, 6 years after the first successful ET in man [94], ET in nonhuman primates was successful in the rhesus monkey [7], the baboon [17] and the cynomolgus monkey [5]. My research group also used ET to the oviduct of cynomolgus monkeys and successfully generated offspring (unpublished data) (Fig. 4). When normal embryos are transferred, the stage in the menstrual cycle of the recipient female must be in synchronization with the corresponding stage in the embryo. Our research strategy was the first to choose sexually mature females with normal menstrual cycles, and then to select from these candidates those females whose cycles were in synchronization with the embryo stage. When cryopreserved embryos are used, this synchronization is relatively simple to control: the embryos are thawed so as to be in synchronization with the menstrual cycle of the recipient, and then they are transferred $[4,54,75,115,119]$.

When either fresh or cryopreserved embryos are used, the ovulation day of the recipient female must be accurately assessed. In one of our studies, we determined

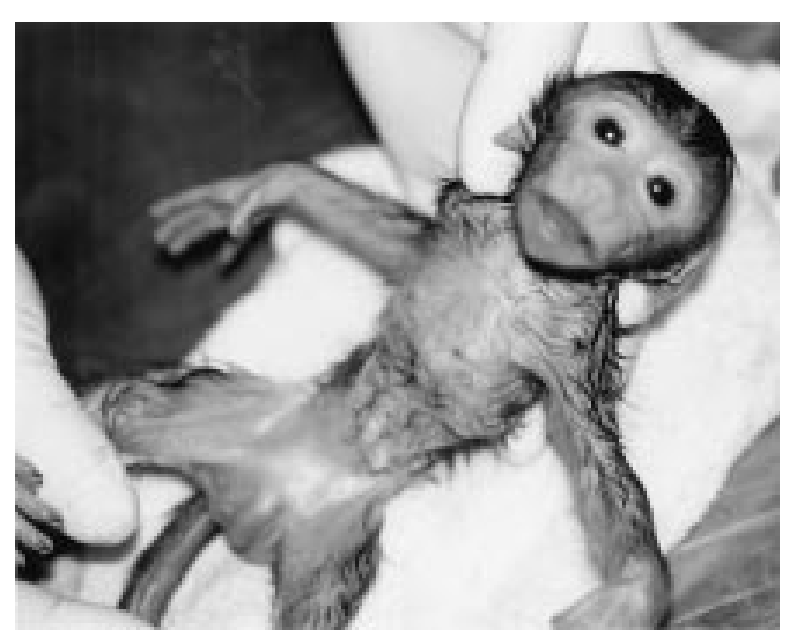

Fig. 4. Male cynomolgus monkey infant, shortly after birth, conceived by IVF and ET. The infant, weighing $340 \mathrm{~g}$, was delivered by Cesarean section 159 days after insemination in vitro. the ovulation day by detecting large changes in the steroid hormone concentration between the pre- and postovulation periods. The method used to measure such concentrations must be very simple, because measurements are taken over several days during the expected pre- and postovulation periods. In recent years much progress has been made towards establishing methods, such as enzyme immunoassays, that are capable of measuring hormones rapidly and with high sensitivity. The ovulation day of cynomolgus monkeys was estimated by measuring the estradiol- $17 \beta$ concentration of steroid hormones, a steroid that is common to all animal species $[68,69]$. In another study, we measured the concentration of progesterone to confirm the presence of functional corpus luteum [69]. We also confirmed that the peptide hormones, such as FSH and lutenizing hormone, in cynomolgus monkeys can be measured by using assay kits developed for such measurements in human subjects [69]. The ovulation day in an individual monkey can therefore be easily and accurately estimated. In our current research we are generating offspring at a high success rate by using recipients whose ovulation day is revealed by using this simple method.

Methods to synchronize menstrual cycles [13, 21, $76]$ or to confirm ovulation [39, 97, 104] have been reported and will be useful for ET.

\section{Conclusion}

This article summarizes the past and present research by my research group in reproductive technology. Described here are our results on in vitro manipulation of spermatozoa and eggs, on establishing embryo manipulation techniques, and on clarifying the mechanisms of fertilization and preimplantation embryo development in nonhuman primates. Basal data from nonhuman primates are being steadily accumulated. In the near future many reproductive physiological phenomena, such as reproductive cell development, fertilization, embryo development, and implantation, will be clarified in detail, and such studies will help in the further development of standard techniques that are practical and comprehensive. 


\section{Acknowledgments}

The studies summarized here were supported in part by a grant from the Ministry of Health and Welfare of Japan, by special coordination funds for promoting Science and Technology, and by a grant from the Japan Health Sciences Foundation. I express my sincere thanks to Mr. H. Tsuchiya and Ms. N. Ogonuki, members of my research group, for their technical support. I also thank the staff of the Tsukuba Primate Center, National Institute of Infectious Diseases, and the staff of the Corporation for Production and Research of Laboratory Primates. Finally, I thank Dr. Y. Yoshikawa of the University of Tokyo for his helpful support.

\section{References}

1. Alak, B.M., Smith, G.D., Woodruff, T.K., Stouffer, R.L., and Wolf, D.P. 1996. Enhancement of primate oocyte maturation and fertilization in vitro by inhibin $A$ and activin A. Fertil. Steril. 66: 646-653.

2. Alak, B.M. and Wolf, D.P. 1994. Rhesus monkey oocytes maturation and fertilization in vitro: Roles of the menstrual cycle phase and of exogenous gonadotropins. Biol. Reprod. 51: 879-887.

3. Balmaceda, J.P., Gastaldi, C., Ord, T., Borrero, C., and Asch, R.H. 1988. Tubal embryo transfer in cynomolgus monkeys: Effects of hyperstimulation and synchrony. Hum. Reprod. 3: 441-443.

4. Balmaceda, J.P., Heitman, T.O., Garcia, M.R., Pauerstein, C.J., and Pool, T.B. 1986. Embryo cryopreservation in cynomolgus monkeys. Fertil. Steril. 45: 403-406.

5. Balmaceda, J.P., Pool, T.B., Arana J.B., Heitman, T.S., and Asch, R.H. 1984. Successful in vitro fertilization and embryo transfer in cynomolgus monkeys. Fertil. Steril. 42: 791-795.

6. Bavister, B.D. and Boatman, D.E. 1992. IVF in nonhuman primate: Current status and future directions. pp. 30-45. In: In vitro fertilization and embryo transfer in primates (Wolf, D.P., Stouffer, R.L., and Brenner, R.M. eds.), Springer-Verlag, New York, USA.

7. Bavister, B.D., Boatman, D.E., Collins, K., Dierschke, D. J., and Eisele, S.G. 1984. Birth of rhesus monkey infant after in vitro fertilization and nonsurgical embryo transfer. Proc. Natl. Acad. Sci. USA 81: 2218-2222.

8. Bavister, B.D., Boatman, D.E., Leibfried, L., Loose, M., and Vernon, M.W. 1983. Fertilization and cleavage of rhesus monkey oocytes in vitro. Biol. Reprod. 28: 983999.

9. Bavister, B.D., Dees, C., and Schultz, R.D. 1986. Refractoriness of rhesus monkeys to repeated ovarian stimulation by exogenous gonadotropins is caused by nonprecipitating antibodies. Am. J. Reprod. Immunol. Microbiol. 11: 11-16.
10. Boatman, D. C. 1987. In vitro growth of nonhuman primate pre- and peri- implantation embryos. pp. 273-308. In: The mammalian preimplantation embryo (Bavister, B.D. ed.), Prenum Press, New York, USA.

11. Boatman, D.E. and Bavister, B.D. 1984. Stimulation of rhesus monkey sperm capacitation by cyclic nucleotide mediators. J. Reprod. Fertil. 71: 357-366.

12. Boatman, D.E., Morgan, P.M., and Bavister, B.D. 1986. Variables affecting the yield and developmental potential of embryos following superstimulation and in vitro fertilization in rhesus monkeys. Gamate Res. 13: 327-338.

13. Bowers, C.L. and Elton, R.H. 1982. Synchronization of menstrual cycles in pigtailed macaques using photoperiod. J. Med. Primatol. 11: 252-256.

14. Brown, C.S. and Loskutoff, N.M. 1998. A training program for noninvasive semen collection in captive western lowland gorillas (Gorilla gorilla gorilla). Zoo Biol. 17: 143-151.

15. Cho, F., Honjo, S. 1973. A simplified method for collecting and preserving cynomolgus macaque semen. Japan. J. Med. Sci. Biol. 26: 261-268.

16. Cho, F., Honjo, S., and Makita, T. 1974. Fertility of frozenpreserved spermatozoa of cynomolgus monkeys. pp. 125-133. In: Contemporary primatology (Kondo, S., Kawai, M., and Ehara, A. eds.), Inuyama Publishers, Japan.

17. Clayton, O. and Kuehl, T.J. 1984. The first successful in vitro fertilization and embryo transfer in a nonhuman primate. Theriogenology 21: 228.

18. Cranfield, M.R., Schaffer, N., Bavister, B.D., Berger, N., Boatman, D.E., Kempske, S., Miner, N., Panos, M., Adams, J., and Morgan, P.M. 1989. Assessment of oocytes retrieved from stimulated and unstimulated ovaries of pig-tailed macaques (Macaca memestrina) as a model to enhance the genetic diversity of captive lion-tailed macaques (Macaca silenus). Zoo Biol. (Suppl 1): 33-46.

19. Denis, L.T., Poindexter, A.N., Ritter, M.B., Seager, S.W.J., and Deter, R.L. 1976. Freeze preservation of squirrel monkey sperm for use in timed fertilization studies. Fertil. Steril. 27: 723-729.

20. Dukelow, W.R., Chan, P.J., Hutz, R.J., Demayo, F.J., Dooley, V.D., Rawlins, R.G., and Ridha, M.T. 1983. Preimplantation development of the primate embryo after in vitro fertilization. J. Exp. Zool. 228: 215-221.

21. Dukelow, W.R., Pierce, D.L., Roudebush, W.E., Jarosz, S.J., and Sengoku, K. 1990. In vitro fertilization in nonhuman primates. J. Med. Primatol. 19: 627-639.

22. Fishel, S., Green, S., Bishop, M., Thornton, S., Hunter, A., Fleming, S., and al-Hassan, S. 1995. Pregnancy after intracytoplasmic injection of spermatid. Lancet 24: 16411642.

23. Flood, J.T., Chillik, C.F., Uem, J.F.H.M., Iritani, A., and Hodgen, G.D. 1990. Ooplasmic transfusion: Prophase germinal vesicle oocytes made developmentally competent by microinjection of metaphase II egg cytoplasm. Fertil. Steril. 53: 1049-1050.

24. Fujisaki, M., Suzuki, M., Kohno, M., Cho, F., and Honjo, S. 1989. Early embryo culture of the cynomolgus monkey (Macaca fascicularis). Am. J. Primatol. 18: 303-313.

25. Ghosh, D. and Sengupta, J. 1992. Patterns of ovulation, 
conception and pre-implantation embryo development during the breeding season in rhesus monkeys kept under semi-natural conditions. Acta Endocrinol. 127: 168-173.

26. Goodeaux, L.L., Anzalone, C.A., Webre, M.K., Graves, K.H., and Voelkel, S.A. 1990. Nonsurgical technique for flushing the Macaca mulatta uterus. J. Med. Primatol. 19: 59-67.

27. Gould, K. G. 1979. Report of the ethics advisory board, appendix: New support of research involving human in vitro fertilization and embryo transfer. 14: 1. U.S. Gov. Printing Off., Washington, D. C., USA.

28. Gould, K.G. 1983. Ovum recovery and in vitro fertilization in the chimpanzee. Fertil. Steril. 40: 378-383.

29. Gould, K.G. 1990. Techniques and significance of gamete collection and storage in the great apes. J. Med. Primatol. 19: 537-551.

30. Gould, K.G., Cline, M.E., and Williams, W.L. 1973. Observations on the induction of ovulation and fertilization in vitro in the squirrel monkey (Saimiri sciureus). Fertil. Steril. 24: 260-268.

31. Gould, K.G. and Styperek, R.P. 1989. Improved methods for freeze preservation of chimpanzee sperm. Am. J. Primatol. 18: 275-284.

32. Hatasaka, H.H., Schaffer, N.E., Chenette, P.E., Kowalski, W., Hecht, B.R., Meehan, T.P., Wentz, A.C., Valle, R.V., Chatterton, R.T., and Jeyendran, R.S. 1997. Strategies for ovulation induction and oocyte retrieval in the lowland gorilla. J. Assist. Reprod. Genet. 14: 102-110.

33. Hewitson, L., Dominko, T., Takahashi, D., Martinovich, C., Ramalho-Santos, J., Sutovsky, P., Fanton, J., Jacob, D., Monteith, D., Neuringer, M., Battaglia, D., Simerly, C., and Schatten, G. 1999. Unique checkpoints during the first cell cycle of fertilization after intracytoplasmic sperm injection in rhesus monkeys. Nature Med. 5: 431-433.

34. Hewitson, L., Takahashi, D., Dominko, T., Simerly, C., and Schatten, G. 1998. Fertilization and embryo development to blastocysts after intracytoplasmic sperm injection in the rhesus monkey. Hum. Reprod. 13: 34493455 .

35. Hiyaoka, A. and Cho, F. 1990. A method for collecting semen by fingers in the African green monkey (Cercopithecus aethiops) and properties of the semen collected. Exp. Anim. 39: 121-124.

36. Honjo, S. 1985. The Japanese Tsukuba Primate Center for Medical Science (TPC): An outline. J. Med. Primatol. 14: 75-89.

37. Honjo, S., Cho, F., and Terao, K. 1984. Establishing the cynomolgus monkey as a laboratory animal: Research on Non-human Primates. pp. 51-79. In: Advance in veterinary science and comparative medicine. 28 (A.G. Hendrickx ed.), Academic Press, New York, USA.

38. Huntress, S.L., Loskutoff, M.M., Raphael, B.L., Yee, B., Bowsher, T.R., Putman, T.M., and Kraemer, D.C. 1989. Pronucleus formation following in vitro fertilization of oocytes recovered from a gorilla (Gorilla gorilla gorilla) with unilateral endometrioid adenocarcinoma of the ovary. Am. J. Primatol. 18: 259-266.

39. Hutz, R. 1994. Technologic advances in the imaging of ovarian morphology and their roles in ascertaining follicular growth and development in the rhesus monkey. Int. J. Primatol. 15: 629-637.

40. Ida, K., Noda, Y., Yano, J., Fukuda, A., Matsumoto, H., and Mori, T. 1988. Ovum recovery and in vitro fertilization in crab-eating monkeys (Macaca fascicularis). Primates 29: $107-116$.

41. Johnson, L.D., Mattson, B.A., Albertini, D.F., Sehgal, P.K., Becker, R.A., Avis, J., and Biggers, J.D. 1991. Quality of oocytes from superovulated rhesus monkeys. Hum. Reprod. 6: 623-631.

42. Joslin, J.O., Weissman, W.D., Johnson, K., Forster, M., Wasser, S., and Collins, D. 1995. In vitro fertilization of Bornean orangutan (Pongo pygmaeus pygmaeus) gametes followed by embryo transfer into a surrogate hybrid orangutan (Pongo pygmaeus). J. Zoo Wildl. Med. 26: 32-42.

43. Kenigsberg, D., Littman, B.A., and Hodgen, G.D. 1986. Induction of ovulation in primate models. Endoc. Rev. 7: 34-43.

44. Kimura, Y. and Yanagimachi, R. 1995. Mouse oocytes injected with testicular spermatozoa or round spermatids can develop into normal offspring. Development 121: 23972405.

45. Koering, M.J., Danforth, D.R., and Hodgen, G.D. 1994. Early follicle growth in the juvenile Macaca monkey ovary: The effects of estrogen priming and follicle stimulating hormone. Biol. Reprod. 50: 686-694.

46. Kraemer, D.C. and Cruz, N.C.V. 1969. Collection, gross characteristics and freezing of baboon semen. J. Reprod. Fertil. 20: 345-348.

47. Kreitmann, O., Lynch, A., Nixon, W.E., and Hodgen, G.D. 1982. Ovum collection, induced luteal dysfunction, in vitro fertilization, embryo development and low tubal ovum transfer in primates. pp. 303-324. In: In vitro Fertilization and Embryo Transfer (Hafez, E.S.E. and Semm K. eds.), MTP Press, Lancaster, UK.

48. Kuehl, T.J. and Dukelow, W.R. 1979. Maturation and in vitro fertilization of follicular oocytes of the squirrel monkey (Saimiri sciureus). Biol. Reprod. 21: 545-556.

49. Lambert, H.L., Citino, S., Collazo, I., and Jeyendran, R.S. 1991. Penetration of zona-free hamster oocytes by ejaculated cryopreserved gorilla spermatozoa. Fertil. Steril. 56: 1201-1203.

50. Lanzendorf, S.E., Gliessman, P.M., Archibong, A.E., Alexander, M., and Wolf, D.P. 1990. Collection and quality of rhesus monkey semen. Mol. Reprod. Dev. 25: 61-66.

51. Lanzendorf, S.E., Gordon, K., Mahony, M., Boyd, C.A., Neely, B., and Hodgen, G.D. 1996. The effect of coculture on the postfertilization development of in vitro-matured monkey oocytes. Fertil. Steril. 65: 420-425.

52. Lanzendorf, S.E., Gordon, K., Toner, J., Mahony, M.C., Kolm, P., and Hodgen, G.D. 1995. Prediction of ovarian response to exogenous gonadotropin stimulation: Utilization for collection of primate oocytes for fertilization in vitro. Theriogenology 44: 641-648.

53. Lanzendorf, S.E., Holmgren, W.J., Schaffer, N., Hatasaka, H., Wentz, A.C., and Jeyendran, R.S. 1992. In vitro fertilization and gamete micromanipulation in the lowland 
gorilla. J. Assist. Reprod. Genet. 9: 358-364.

54. Lanzendolf, S.E., Zelinski, M.B., Stouffer, R.L., and Wolf, D.P.1990. Maturity at collection and the developmental potential of rhesus monkey oocytes. Biol. Reprod. 42: 703711.

55. Leverage, W.E., Valerio, D.A., Schultz, A.P., Kingsbury, E., and Dorey, C. 1972. Comparative study on the freeze preservation of spermatozoa, primate, bovine, and human. Lab. Anim. Sci. 22: 882-889.

56. Li, M.W., Yudin, A.I., VandeVoort, C.A., Sabeur, K., Primakoff, P., and Overstreet, J.W. 1997. Inhibition of monkey sperm hyaluronidase activity and heterologous cumulus penetration by flavonoids. Biol. Reprod. 56: 13831389.

57. Liang, J.H., Sankai, T., Yoshida, T., Cho, F., and Yoshikawa, Y. 1997. Use of rota-cut needle for testicular biopsy in cynomolgus monkeys (Macaca fascicularis). Comtemp. Topics (Am. Assoc. Lab. Anim. Sci.) 36: 77-79.

58. Lopata, A., Summers, P.M., and Hearn, J.P. 1988. Births following the transfer of cultured embryos obtained by in vitro and in vivo fertilization in the marmoset monkey (Callithrix jacchus). Fertil. Steril. 50: 503-509.

59. Mahi, C.A. and Yanagimachi, R. 1978. Capacitation, acrosome reaction, and egg penetration by canine spermatozoa in a simple defined medium. Gamete Res. 1: 101-109.

60. Mahone, J.P. and Dukelow, W.R. 1978. Sperm preservation in Macaca fascicularis. Lab. Anim. Sci. 28: 556-561.

61. Mahony, M.C., Oehninger, S., Doncel, G., Morshedi, M., Acosta, A., and Hodgen, G.D. 1993. Functional and morphological features of spermatozoa microaspirated from the epididymal regions of cynomolgus monkeys (Macaca fascicularis). Biol. Reprod. 48: 613-620.

62. Matsubayashi, K. 1982. Comparison of the two methods of electroejaculation in the Japanese monkey (Macaca fuscata). Exp. Anim. 31: 1-6.

63. Meng, L., Ely, J.J., Stouffer, R.L., and Wolf, D.P. 1997. Rhesus monkey produced by nuclear transfer. Biol. Reprod. 57: 454-459.

64. Meng, L. and Wolf, D.P. 1997. Sperm-induced oocyte activation in the rhesus monkey: nuclear and cytoplasmic changes following intracytoplasmic sperm injection. Hum. Reprod. 12: 1062-1068.

65. Morgan, P.M., Hutz, R.J., Kraus, E.M., Cormie, J.A., Dierschke, D.J., and Bavister, B.D. 1987. Evaluation of ultrasonography for monitoring follicular growth in rhesus monkeys. Theriogenology 27: 769-780.

66. Morgan, P.M., Warikoo, P.K., and Bavister, B.D. 1991. In vitro maturation of ovarian oocytes from unstimulated rhesus monkeys: Assessment of cytoplasmic maturity by embryo development after in vitro fertilization. Biol. Reprod. 45: 89-93.

67. Ogonuki, N., Sankai, T., Cho, F., Sato, K., and Yoshikawa, Y. 1998. Comparison of two methods of assisted fertilization in cynomolgus monkeys (Macaca fascicularis): Intracytoplasmic sperm injection and pertial zona dissection followed by insemination. Hum. Reprod. 13: 2555-2560.

68. Ogonuki, N., Sankai, T, Tsuchiya, H., Matsumuro, M.,
Yoshida, T., Cho, F., and Yoshikawa, Y. 1997. Estimation of the day of ovulation in cynomolgus monkeys (Macaca fascicularis) by measuring serum estradiol concentrations on the same day as blood-sampling. Jpn. J. Fertil. Steril. 42: 136-140 (in Japanese with English summary).

69. Ogonuki, N., Tsuchiya, H., Sankai, T., Yoshida, T., and Cho, F. 1997. Measurement of reproductive hormones in cynomolgus monkeys (Macaca fascicularis) using an enzyme immunoassay kit for humans. pp. 883-886. In: Adv. Comp. Endocrinol. (Kawashima, S. and Kikuyama, S. eds.), Monduzzi Editore S.p.A., Italy.

70. Ogura, A., Matsuda, J., and Yanagimachi, R. 1994. Birth of normal young following fertilization of mouse oocytes with round spermatids by electrofusion. Proc. Natl. Acad. Sci. USA 91:7460-7462.

71. Pierce, D.L., Johnson, M.P., Kaneene, J.B., and Dukelow, W.R. 1993. In vitro fertilization analysis of squirrel monkey oocytes produced by various follicular induction regimens and the incidence of triploidy. Am. J. Primatol. 29: 37-48.

72. Pope, C.E., Dresser, B.L., Chin, N.W., Liu, J.H., Loskutoff, N.M., Behnke, E.J., Brown, C., Mcrae, M., Sinoway, C.E., Campbell, M.K., Cameron, K.N., Owens, O.M., Johnson, C.A., Evans, R.R., and Cedars, M.I. 1997. Birth of a western lowland gorilla (Gorilla gorilla gorilla) following in vitro fertilization and embryo transfer. Am. J. Primatol. 41: 247260.

73. Pope, C.E., Pope, V.Z., and Beck, L.R. 1980. Nonsurgical recovery of uterine embryos in the baboon. Biol. Reprod. 23: 657-662.

74. Pope, C.E., Pope, V.Z., and Beck, L.R. 1982. Development of baboon preimplantation embryos to post-implantation stages in vitro. Biol. Reprod. 27: 915-923.

75. Pope, C.E., Pope, V.Z., and Beck, L.R. 1984. Live birth following cryopreservation and transfer of a baboon embryo. Fertil. Steril. 42: 143-145.

76. Pope, N. S. and Gould, K. G. 1990. Synchronization of the menstrual cycle through the use of an oral progestin in the rhesus monkey. Theriogenology 34: 133-137.

77. Roussel, J.D. and Austin, C.R. 1967. Preservation of primate spermatozoa by freezing. J. Reprod. Fertil. 13: 333-335.

78. Sankai, T., Cho, F., and Yoshikawa, Y. 1997. In vitro fertilization and preimplantation embryo development of African green monkeys (Cercopithecus aethiops). Am. J. Primatol. 43: 43-50.

79. Sankai, T., Fujisaki, M., Ida, S., Wakabayashi, T., Cho, F., and Honjo, S. 1991. Successful in vitro culture to the blastocyst stage of cynomolgus monkey (Macaca fascicularis) eggs fertilized in vitro. J. Fertil. Implant. (Tokyo) 8: 76-78 (in Japanese with English summary).

80. Sankai, T., Ogonuki, N., Tsuchiya, H., Shimizu, K., Cho, F., and Yoshikawa, Y. 1998. Comparison of results from IVF-related studies for cynomolgus monkeys, Japanese monkeys, African green monkeys, and red-bellied tamarins. J.Fertil. Implant. (Tokyo) 15: 177-179.

81. Sankai, T., Sakakibara, I., Cho, F., and Yoshikawa, Y. 1993. In vitro maturation and in vitro fertilization of eggs recovered from ovaries of cynomolgus monkeys (Macaca fascicularis) at necropsy in a indoor breeding colony. J. Mamm. Ova Res. 
10: 161-166 (in Japanese with English summary).

82. Sankai, T., Shimizu, K., Cho, F., and Yoshikawa, Y. 1994. In vitro fertilization using Japanese monkey (Macaca fuscata) eggs and cynomolgus monkey (Macaca fascicularis) frozen/thawed spermatozoa. Exp. Anim. 43: 45-50 (in Japanese with English summary).

83. Sankai, T., Shimizu, K., Cho, F., and Yoshikawa Y. 1997. In vitro fertilization of follicular oocytes by frozen-thawed spermatozoa in Japanese monkeys (Macaca fuscata). Lab. Anim. Sci. 47: 58-62.

84. Sankai, T., Terao, K., Yanagimachi, R., Cho, F., and Yoshikawa, Y. 1994. Cryopreservation of spermatozoa from cynomolgus monkeys (Macaca fascicularis). J. Reprod. Fertil. 101: 273-278.

85. Sankai, T., Tsuchiya, H., Ogonuki, N., Cho, F., and Yoshikawa, Y. 1997. A trial of oocyte maturation and in vitro fertilization by frozen-thawed spermatozoa in the redbellied tamarin (Saguinus labiatus). J. Mamm. Ova Res. 14: 205-208.

86. Schenken, R.S., Williams, R.F., and Hodgen, G.D. 1984. Ovulation induction using "pure" follicle-stimulating hormone in monkeys. Fertil. Steril. 41: 629-634.

87. Schramm, R.D. and Bavister, B.D. 1996. Development of in-vitro-fertilized primate embryos into blastocysts in a chemically defined, protein-free culture medium. Hum. Reprod. 11: 1690-1697.

88. Schramm, R.D. and Bavister, B.D. 1996. Granulosa cells from follicle stimulating hormone-primed monkeys enhance the developmental competence of in-vitro-matured oocytes from non-stimulated rhesus monkeys. Hum. Reprod. 11: 1698-1702.

89. Schramm, R.D., Tennier, M.T., Boatman, D.E., and Bavister, B.D. 1993. Chromatin configurations and meiotic competence of oocytes are related to follicular diameter in nonstimulated rhesus monkeys. Biol. Reprod. 48: 349-356.

90. Seier, J.V., Conradie, E., Oettle, E.E., and Fincham, J.E. 1993. Cryopreservation of vervet monkey semen and recovery of progressively motile spermatozoa. J. Med. Primatol. 22: 355-359.

91. Seshagiri, P.B., Bridson, W.E., Dierschke, D.J., Eisele, S.G., and Hearn, J.P. 1993. Non-surgical uterine flushing for the recovery of preimplantation embryos in rhesus monkeys: Lack of seasonal infertility. Am. J. Primatol. 29: 81-91.

92. Seshagiri, P.B. and Hearn, J.P. 1993. In-vitro development of in-vivo produced rhesus monkey morulae and blastocysts to hatched, attached, and post-attached blastocyst stages: Morphology and early secretion of chorionic gonadotrophin. Hum. Reprod. 8: 279-287.

93. Smith, G.D., Sadhu, A., and Wolf, D.P. 1998. Transient exposure of rhesus macaque oocytes to calyculin-A and okadaic acid stimulates germinal vesicle breakdown permitting subsequent development and fertilization. Biol. Reprod. 58: 880-886.

94. Steptoe, P.C. and Edwards, R.G. 1978. Birth after the reimplantation of a human embryo. (letter) Lancet 2: 366.

95. Summers, P.M., Campbell, J.M., and Miller, M.W. 1988. Normal in-vivo development of marmoset monkey embryos after trophectoderm biopsy. Hum. Reprod. 3: 389-393.
96. Summers, P.M., Taylor, C.T., and Hearn, J.P. 1987. Characteristics of trophoblastic tissue derived from in vitro culture of preimplantation embryos of the common marmoset monkey. Placenta 8: 411-422.

97. Tardif, S.D., Lacker, H.M., and Feuer, M. 1993. Follicular development and ovulation in the marmoset monkey as determined by repeated laparoscopic examination. Biol. Reprod. 48: 1113-1119.

98. Thomson, J.A., Iliff-Sizemore, S.A., Gliessman, P.M., and Wolf, D.P. 1992. Collection and fertilization potential of sperm from the Sulawesi crested black macaque (Macaca nigra). Am. J. Primatol. 28: 289-297.

99. Thomson, J.A., Kalishman, J., Golos, T.G., Durning, M., Harris, C.P., Becker, R.A., and Hearn, J.P. 1995. Isolation of a primate embryonic stem cell line. Proc. Natl. Acad. Sci. USA 92: 7844-7848.

100. Tollner, T.L., VandeVoort, C.A., Overstreet, J.W., and Drobnis, E.Z. 1990. Cryopreservation of spermatozoa from cynomolgus monkeys (Macaca fascicularis). J. Reprod. Fertil. 90: 347-352.

101. Torii, R., Hosoi, Y., Masuda, Y., Iritani, A., and Nigi, H. 2000. Birth of Japanese monkey (Macaca fuscata) infant following in vitro fertilization and embryo transfer. Primates 41: 39-47.

102. Torii, R. and Nigi, H. 1998. Successful artificial insemination for indoor breeding in the Japanese monkey (Macaca fuscata) and the cynomolgus monkey (Macaca fascicularis). Primates 39: 399-406.

103. Toyoda, Y., Yokoyama, M., and Hoshi, F. 1971. Studies on the fertilization of mouse eggs in vitro. I. In vitro fertilization of eggs by fresh epididymal sperm. Jpn. J. Anim. Reprod. 16: 147-151 (in Japanese with English summary).

104. Tsuchiya, H., Ogonuki, N., Yoshida, T., Cho, F., Yoshikawa, Y., Ito, M., and Sankai, T. 1998. Changes in the electrical impedance level of vaginal mucus during the menstrual cycle in cynomolgus monkeys (Macaca fascicularis). Lab. Anim. Sci. 48: 535-537.

105. VandeVoort, C. A. and Tarantal, A.F. 1991. The macaque model for in vitro fertilization: Superovulation techniques and ultrasound-guided follicular aspiration. J. Med. Primatol. 20: 110-116.

106. VandeVoort, C.A., Tollner, T.L., and Overstreet, J.W. 1992. Sperm-zona pellucida interaction in cynomolgus and rhesus macaques. J. Andrology 13: 428-432.

107. VandeVoort, C.A., Yudin, A.I., and Overstreet, J.W. 1997. Interaction of acroseme-reacted macaque sperm with macaque zona pellucida. Biol. Reprod. 56: 1307-1316.

108. Wakayama, T., Perry, A.C.F., Zuccotti, M., Johnson, K. R., and Yanagimachi, R. 1998. Full-term development of mice from enucleated oocytes injected with cumulus cell nuclei. Nature 394: 369-374.

109. Weston, A.M. and Wolf, D.P. 1996. Differential preimplantation development of rhesus monkey embryos in serum-supplemented media. Mol. Reprod. Dev. 44: 8892.

110. Whitten, W.K. 1971. Nutritional requirements for the culture of preimplantation embryos in vitro. Adv. Biosci. 
6: 129-139.

111. Wilmut, I., Schnieke, A.E., McWhir, J., Kind, A.J., and Campbell, K.H.S. 1997. Viable offspring derived from fetal and adult mammalian cells. Nature 385: 810-813.

112. Wilton, L.J., Marshall, V.S., Piercy, E.C., and Moore, H.D.M. 1993. In vitro fertilization and embryo development in the marmoset monkey (Callithrix jacchus). J. Reprod. Fertil. 97: 481-486.

113. Wolf, D.P., Meng, L., Ouhibi, N., and Zelinski-Wooten, M. 1999. Nuclear transfer in the rhesus monkey: Practical and basic implications. Biol. Reprod. 60: 199-204.

114. Wolf, D.P., Thomson, J.A., Zelinski-Wooten, M.B., and Stouffer, R.L. 1990. In vitro fertilization-embryo transfer in nonhuman primates: The technique and its applications. Mol. Reprod. Dev. 27: 261-280.

115. Wolf, D.P., VandeVoort, C.A., Haas, G.R., Wooten, M.B., Hess, D.L., Baughman, W.L., and Stouffer, R.L. 1989. In vitro fertilization and embryo transfer in the rhesus monkey. Biol. Reprod. 41: 335-346.

116. Yanagimachi, R., Lopata, A., Odom, C.D., Bronson, R.A., Mahi, C.A., and Nicolson, G.L. 1979. Retention of biologic characteristics of zona pellucida in highly concentrated salt solution: The use of salt-stored eggs for assessing the fertilizing capacity of spermatozoa. Fertil Steril. 31: 562-574.

117. Yeoman, R.R., Helvacioglu, A., Williams, L.E., Aksel, S., and Abee, C.R. 1994. Restoration of oocyte maturational competency during the nonbreeding season with follicle-stimulating hormone stimulation in squirrel monkeys (Saimiri boliviensis boliviensis). Biol. Reprod. 50: 329-335.
118. Yeoman, R.R., Ricker, R.B., Williams, L.E., Sonksen, J., and Abee, C.R. 1997. Vibratory stimulation of ejaculation yields increased motile spermatozoa, compared with electroejaculation, in squirrel monkeys (Saimiri boliviensis). Comtemp. Topics (Am. Assoc. Lab. Anim. Sci.) 36: 62-64.

119. Younis, A.I., Toner, M., Albertini, D.F., and Biggers, J.D. 1996. Cryobiology of non-human primate oocytes. Hum. Reprod. 11: 156-165.

120. Zelinski-Wooten, M.B., Hess, D.L., Baughman, W.L., and Molskness, T.A. 1993. Administration of an aromatase inhibitor during the late follicular phase of gonadotropintreated cycles in Rhesus monkeys: effects on follicle development, oocyte maturation, and subsequent luteal function. J. Clin. Endocrinol. Metab. 76: 988-995.

121. Zelinski-Wooten, M.B., Hess, D.L., Wolf, D.P., and Stouffer, R.L. 1994. Steroid reduction during ovarian stimulation impairs oocyte fertilization, but not folliculogenesis, in rhesus monkeys. Fertil. Steril. 61: $1147-1155$.

122. Zelinski-Wooten, M.B., Lanzendorf, S.E., Wolf, D.P., Aladin Chandrasekher, Y., and Stouffer, R.L. 1991. Titrating luteinizing hormone surge requirements for ovulatory changes in primate follicles. I. oocyte maturation and corpus luteum function. J. Clin. Endocrinol. Metab. 73: 577-583.

123. Zhang, L., Weston, A.M., Denniston, R.S., Goodeaux, L.L., Godke, R.A., and Wolf, D.P. 1994. Developmental potential of rhesus monkey embryos produced by in vitro fertilization. Biol. Reprod. 51: 433-440. 